Portland State University

PDXScholar

Civil and Environmental Engineering Faculty

Publications and Presentations

Civil and Environmental Engineering

$1-2015$

\title{
Modeling the Effects of Congestion on Fuel Economy for Advanced Power Train Vehicles
}

\author{
Alexander Y. Bigazzi \\ Portland State University, abigazzi@gmail.com \\ Kelly J. Clifton \\ Portland State University, kclifton@pdx.edu
}

Follow this and additional works at: https://pdxscholar.library.pdx.edu/cengin_fac

Part of the Civil and Environmental Engineering Commons

Let us know how access to this document benefits you.

\section{Citation Details}

Bigazzi, Alexander Y. and Clifton, Kelly J., "Modeling the Effects of Congestion on Fuel Economy for Advanced Power Train Vehicles" (2015). Civil and Environmental Engineering Faculty Publications and Presentations. 182.

https://pdxscholar.library.pdx.edu/cengin_fac/182

This Post-Print is brought to you for free and open access. It has been accepted for inclusion in Civil and Environmental Engineering Faculty Publications and Presentations by an authorized administrator of PDXScholar. Please contact us if we can make this document more accessible: pdxscholar@pdx.edu. 

ECONOMY FOR ADVANCED POWERTRAIN VEHICLES

4 Alexander Bigazzi

5 Department of Civil and Environmental Engineering

6 Portland State University

7 P.O. Box 751, Portland, OR 97207-0751

8 abigazzi@pdx.edu

9 503-725-4282

Kelly Clifton

12 Department of Civil \& Environmental Engineering

13 Portland State University

14 P.O. Box 751, Portland, OR 97207-0751

15 kclifton@pdx.edu

Brian Gregor

18 Transportation Planning Analysis Unit

19 Oregon Department of Transportation

20555 13th Street NE, Suite 2, Salem, OR 97301-4178

21 Brian.J.Gregor@odot.state.or.us

22

Submitted to the $91^{\text {st }}$ Annual Meeting of the Transportation Research Board, January 2012,

26 Washington, D.C.

27

28

29 Original Submission: July 2011

30 Revised: November 2011

31

32

337,377 words [5,377 + 2 table x250 + 6 figures x250] 


\section{ABSTRACT}

This paper describes research undertaken to establish plausible fuel-speed curves (FSC) for hypothetical advanced powertrain vehicles. These FSC are needed to account for the effects of congestion in long-term transportation scenario analysis considering fuel consumption and emissions. We use the PERE fuel consumption model with real-world driving schedules and a range of vehicle characteristics to estimate fuel economy (FE) in varying traffic conditions for light-duty internal combustion engine (ICE) vehicles, hybrid gas-electric vehicles (HEV), fully electric vehicles (EV), and fuel cell vehicles (FCV). FSC are fit to model results for each of 145 hypothetical vehicles. Analysis of the FSC shows that advanced powertrain vehicles are expected to perform proportionally better in congestion than ICE vehicles (when compared to their performance in free-flow conditions). HEV are less sensitive to average speed than ICE vehicles, and tend to maintain their free-flow FE down to $20 \mathrm{mph}$. FE increases for EV and FCV from free-flow conditions down to about 20-30 mph. Beyond powertrain type differences, relative FE in congestion is expected to improve for vehicles with less weight, smaller engines, higher hybrid thresholds, and lower accessory loads (such as air conditioning usage). Relative FE in congestion also improves for vehicle characteristics that disproportionately reduce efficiency at higher speeds, such as higher aerodynamic drag and rolling resistance. In order to implement these FSC for scenario analysis, we propose a bounded approach based on a qualitative characterization of the future vehicle fleet. The results presented in this paper will assist analysis of the roles that vehicle technology and congestion mitigation can play in reducing fuel consumption and emissions from roadway travel.

\section{$57 \quad 1$ Introduction}

Traffic congestion has been steadily increasing in the U.S. for decades [1]. Increasing levels of congestion lead to longer travel times, lower average speeds, and increased vehicle speed variability. These affect engine/motor operating loads and operating duration, which in turn affect fuel efficiency. At the same time, the U.S. vehicle fleet continues to evolve, with new powertrain types such as Hybrid Electric Vehicles (HEV), Fuel Cell Vehicles (FCV), and fully Electric Vehicles (EV) [2]. This paper addresses how these new vehicle technologies will respond to congestion, in terms of fuel efficiency. The Oregon Department of Transportation (ODOT) has developed a model to forecast transportation-related greenhouse gas emissions, called the Greenhouse gas Statewide Transportation Emissions Planning model or GreenSTEP [3]. GreenSTEP is a modeling tool that can be used to assess the impact of a range of policies and other factors on transportation-related greenhouse gas emissions. It is designed to operate within the context of the large uncertainties of long-term transportation planning. One of the improvements needed in the model is the ability to account for the impact of future technological changes on vehicle fuel efficiency in congestion.

Vehicle fuel efficiency can be expressed as Fuel Economy (FE), in travel distance per

73 unit volume of fuel - in the U.S. as miles per gallon (mpg). Fuel-Speed Curves (FSC) summarize 
the relationship between vehicle fuel economy and congestion level (indicated by travel speed) for average, aggregate conditions. Thus FSC can serve to estimate fuel consumption in congestion for macroscopic traffic and transportation models.

In the GreenSTEP model, normalized FSC are used to adjust average fuel efficiencies for varying levels of metropolitan congestion. While FSC for conventional, Internal Combustion Engine (ICE) vehicles have been previously studied (and adopted in GreenSTEP), FSC for advanced powertrain vehicles have received less attention. In order to enable incorporation of the impacts of congestion on advanced vehicles in GreenSTEP, this research develops FSC for HEV, FCV, and EV. Fuel economy at varying average travel speeds is estimated using an advancedvehicle fuel consumption model with archetypal speed profiles. Then, representative FSC are estimated for each vehicle type, based on a range of vehicle characteristics. The next section describes relevant background information and literature, and is followed by a presentation of the modeling methodology. Then, results for FSC calculation are show, followed by a section discussing of the application of these FSC for transportation scenario analysis.

\section{Background and Literature}

\subsection{Congestion and Fuel Economy}

Traffic congestion affects vehicle fuel economy through lower average travel speed and increased vehicle speed variability (accelerations and decelerations). These influence engine/motor operating loads and operating duration, which in turn impact fuel consumption per mile of travel [4]. FSC show these aggregate relationships as the expected average FE at a given average travel speed, including typical acceleration and deceleration activity (often for specific vehicle and roadway types). In this way the speed variable in FSC is a proxy for congestion level, indicative of both average speed and speed variability for archetypal conditions.

FSC are the fuel equivalent of Emissions-Speed Curves (ESC), which are used to estimate the aggregate impact of congestion on vehicle pollution emissions rates [5-7]. The ESC approach has been shown to adequately represent congestion effects (related to both average speed and speed variability) if the curves are based on representative, real-world driving patterns [8], [9]. The EPA has created a set of realistic driving schedules (driving patterns) for inclusion in their MOVES 2010 mobile-source emissions model [10], [11]. Existing research on FSC for ICE vehicles indicates that increasing levels of congestion - with lower average speeds generally lead to increased fuel consumption rates [6]. At very high speeds, however, fuel consumption rates increase as well, and there is an optimal average speed for fuel economy which depends on the vehicle fleet - typically between 45 and $65 \mathrm{mph}$ [12].

\subsection{Fuel Economy of Advanced Vehicles}

Given concerns about energy consumption and climate impacts of the U.S. vehicle fleet, there has been considerable attention paid to the potential fuel economy of advanced powertrain vehicles [2], [4], [13], [14]. Fuel economy estimates for advanced vehicles are challenging because few, if any, dynamometer test data are available. Thus, vehicle fuel consumption 
112 modeling is often undertaken to estimate or predict the performance of these vehicles. Various

113 studies have demonstrated or predicted substantial fuel consumption or greenhouse gas

114 emissions savings from the substitution of advanced powertrain vehicles for conventional 115 Internal Combustion Engine (ICE) vehicles in the fleet [2], [15-17].

$116 \quad$ Fuel consumption modeling for advanced vehicles has focused on average overall fuel 117 economy. But speed-based or congestion-based FE estimates are needed to predict the effects of 118 varying congestion levels on the performance of these vehicles. Delorme, Karbowski, \& Sharer 119 [18] modeled the speed-dependent fuel consumption rates of select medium and heavy-duty 120 vehicles, including several hybrid versions. They point out the importance of using realistic 121 driving patterns and the challenge of a lack of a standard set of vehicle technical specifications 122 for advanced vehicle modeling. Fontaras, Pistikopoulos, and Samaras [19] modeled two hybrid 123 passenger cars and found lower optimal speeds with respect to fuel consumption for the hybrid 124 cars than for conventional cars (and lower overall fuel consumption rates). While modeling such 125 as this suggests different FSC for advanced vehicles than for ICE vehicles, these studies do not 126 provide the array of FSC needed for scenario testing of a variety of potential advanced vehicles 127 in congestion.

128 Beyond the unique mechanical performance of advanced vehicles, some studies have 129 suggested that advanced vehicles are driven differently. An empirical study by the EPA in 130 Kansas City showed less aggressive driving for HEV than for ICE vehicles [11]. The report 131 acknowledges, however, that there are several other possible explanations besides driver 132 behavior change in response to HEV/ICE vehicle differences. Other possibilities include less 133 power available in the test hybrid vehicles and self-selection of fuel-conscious drivers for hybrid 134 ownership. Alessandrini \& Orecchini [20] studied EV operating in Rome and also found less 135 aggressive driving - presumably owing to the limited power of the vehicles.

136

138

139

140

141

142

143

144

145

\subsection{Modeling Congestion in GreenSTEP}

In order to motivate the study methodology, we here describe the role of FSC within GreenSTEP. Average fleet fuel economy by vehicle type and model year is input to each model run. GreenSTEP accounts for congestion effects by adjusting the fleet-average fuel economy (for ICE vehicles only). For each metropolitan area, the Daily Vehicle Miles Traveled (DVMT) are distributed by average speed (average speed ranges are 25-60 mph on freeways and 21-30 mph on arterials). Then, normalized FSC are used to scale the average fleet fuel economy based on the estimated speed distribution of DVMT. Details can be found in the GreenSTEP documentation [3]. The next section describes the modeling methodology of this study, which attempts to develop realistic FE adjustment curves at the GreenSTEP scope of modeling.

\section{Methodology}

In order to estimate the impacts of congestion on advanced technology vehicles, this research develops FSC for light-duty ICE vehicles, HEV, FCV, and EV. An overview of the modeling procedure is illustrated in Figure 1. First, a large set of real-world driving schedules (a) 
and a test set of 145 hypothetical vehicles with a variety of characteristics (b) are used as inputs to the PERE model (c) to estimate fuel consumption rates by Vehicle Specific Power (VSP) bin (e) for each vehicle. Next, the same set of driving schedules (a) and vehicle characteristics (b) are used to calculate (d) VSP bin distributions of operating time for each driving schedule, for each vehicle (f). The driving schedules represent a variety of congestion levels on freeway and arterial facilities. Combining (e) and (f) generates estimates of average FE for each driving schedule, for each vehicle (g). We fit these FE estimates to a curve as a function of the average speed for each driving schedule, producing a FSC for each vehicle on each facility type (h). Finally, the freeway and arterial FSC for each vehicle are normalized to the average speeds implied by EPA test driving schedules (i). Section 5 describes a proposed method for implementation of these normalized FSC in a long-range scenario analysis tool. We next describe components of the modeling methodology in more detail.

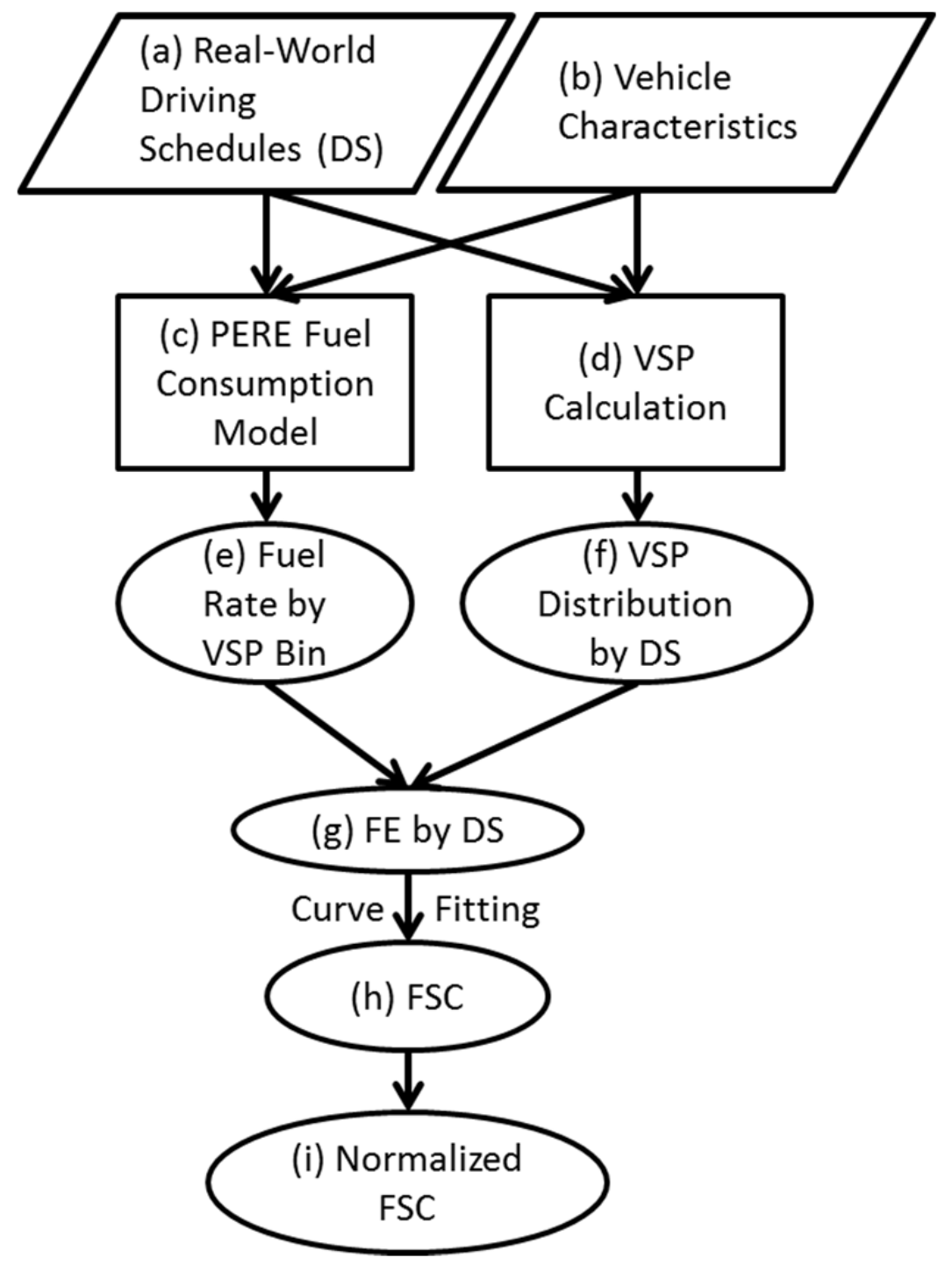




\subsection{Fuel Consumption Model}

Based on an investigation of potential fuel consumption models, the Physical Emissions Rate Estimator (PERE) is selected as the most appropriate model for this research [4]. PERE is a physical vehicle fuel consumption model developed by the EPA to supplement the MOVES mobile-source emissions model for untested vehicles. PERE adopts a physical approach (similar to the well-known Comprehensive Modal Emissions Model [21]) that is ideal for advanced vehicle technologies without vehicle test data. It also utilizes parameters that are aligned with the scope of vehicle-class modeling performed here. PERE models vehicles in less detail than individual vehicle models such as ADVISOR [13] - which is a limitation in some contexts but appropriate for macroscopic scenario analysis where vehicle characteristics are uncertain.

The primary vehicle input parameters for PERE (in general order of importance as indicated in the PERE documentation) are:

1. Vehicle type

2. Engine indicated (thermal) efficiency

3. Vehicle model year

4. Road load power (method and coefficients)

5. Vehicle weight

6. Engine size (displacement)

7. Motor peak power (HEV/EV only)

8. Fuel cell power rating (FCV only)

9. Hybrid threshold (HEV only)

10. Powertrain type (ICE, HEV, EV, FCV)

11. Fuel type (gas or diesel for ICE - representing spark-ignition or compression-ignition engines)

12. Transmission type (automatic or manual)

The details and model sensitivity for these parameters are discussed in the PERE documentation [4]. In addition to the vehicle parameters, PERE modeling requires an input driving schedule. The driving schedule is a time series of second-by-second vehicle speeds. Vehicle acceleration is differentiated from the speeds, and VSP is calculated using a Road Load Power method, described in the documentation. VSP is a proxy for engine loading, widely used in vehicle emissions and fuel consumption modeling [22], [23].

There are two primary caveats of the PERE modeling approach: 1) PERE only models parallel-configuration HEV, not series-configuration, and 2) the application of PERE for EV has not yet been validated. The first is not major concern, since not all possible advanced-vehicle powertrain configurations can be included at this scale of analysis. The second is more of a concern, but a reasonable limitation given the lack of available validation data at the time of development. There are still few data available on the real-world fuel consumption performance of EV, and PERE is considered the best available tool for this study. It lends confidence to the modeling of EV in PERE that EV are modeled as modified HEV (with the ICE removed), and the HEV model in PERE has been well validated [4]. 


\subsection{Strategy for Implementing PERE}

The PERE documentation describes a method for using PERE to derive advanced vehicle fuel consumption rates for MOVES modeling [4]. By this method, the vehicles of interest are modeled over a combination of transient driving schedules, and the average fuel consumption rates binned by the 17 VSP bins used in MOVES [11]. With fuel rates tabulated by VSP bin for each vehicle, total fuel consumption can be quickly computed from the VSP-distribution of second-by-second vehicle activity.

Vehicle activity distribution by VSP can be computed from speed profiles - such as embodied in driving schedules [24]. Using coastdown coefficients A, B, and C (also known as Road Load Coefficients - RLC) from the dynamometer load equation, VSP is calculated as

$$
V S P=\mathrm{A} \frac{v}{m}+\mathrm{B} \frac{v^{2}}{m}+\mathrm{C} \frac{v^{3}}{m}+1.1 v(a+g * \text { grade })
$$

from [4], where VSP is in $\mathrm{kW} / \mathrm{Mg}, v$ is speed in $\mathrm{m} / \mathrm{s}, a$ is acceleration in $\mathrm{m} / \mathrm{s}^{2}, g$ is the acceleration due to gravity in $\mathrm{m} / \mathrm{s}^{2}$, and $m$ is vehicle mass in Mg. The three RLC correspond to rolling, rotating, and aerodynamic resistive factors, respectively [4].

The RLC, if not provided as a vehicle parameter, can be estimated from the vehicle mass or the Track Road Load HorsePower (TRLHP) [4], [25]. This approach of using many driving schedules to estimate fuel rates by VSP bin then distributing activity by VSP bin provides more fuel consumption data in each VSP bin and more vehicle activity flexibility than simply using a single driving schedule to model fuel rate at an average speed.

The adopted strategy for advanced vehicle modeling in this research mirrors the PEREMOVES approach. The additional benefit of this approach is that vehicle activity distributions by VSP bin can be adjusted based on projected changes in roadway operations, vehicle performance, or driver behavior. In this way fuel-speed curves can be sensitive to changing traffic operations and driving behaviors without repeating the engine/fuel modeling process.

\subsection{Driving Schedules}

The EPA has generated facility-specific driving schedules (included in the MOVES model) for different levels of congestion based on real-world measurements. The MOVES driving schedules are designed to reflect actual on-road vehicle activity (in contrast to the standardized dynamometer test schedules), and so represent actual congestion effects [9], [10]. The MOVES database includes 18 relevant Light-Duty (LD) driving schedules on freeways and arterials with average speeds from 3 to $76 \mathrm{mph}$. Concatenating the relevant MOVES driving schedules for modeling in PERE leads to a long (3.7 hour) composite driving schedule for binned fuel rate estimates. As discussed above, it is possible that new engine/powertrain technologies could influence driving patterns for certain speed-facility combinations. Given the uncertainty that this is a real effect - and if it is real, what exactly the effect would be - we use the same driving schedules for all vehicles modeled. 
In addition to the MOVES driving schedules, we apply real-world vehicle speed data collected on an urban freeway in Portland, Oregon. Vehicle speed data were gathered on OR-217 in the summer and fall of 2010 using second-by-second Global Positioning System (GPS) data in a probe vehicle (passenger car). This freeway had average daily traffic of about 100,000 vehicles in 2009 [26], with regular peak-period congestion in both directions. In total, 59 probe vehicle runs of 6.4 miles each were collected before, during, and after the PM peak period. This produced over ten hours of data, with average speeds on each run from 18 to $54 \mathrm{mph}$. Lastly, fuel economy is also estimated for the set of EPA test driving schedules used for fuel economy labeling [11].

\subsection{Vehicle Characteristics}

FSC are generated for the following light-duty vehicle types: conventional ICE (sparkignition and compression-ignition), HEV, EV, and FCV. Vehicle parameter assumptions as required by PERE are based on a variety of sources. Many representative characteristics are included as defaults within the PERE model (transmission shift points, mechanical efficiency, etc.). Other vehicle characteristics are based on the literature - vehicle projection studies and similar research on future vehicle performance [2], [4], [11], [12], [14], [18], [27], [28]. Some vehicle characteristics (such as RLC) are based on EPA inventory data and modeling guidance for the U.S. vehicle fleet [27].

Additionally, some vehicles' characteristics are based on manufacturers' specifications. including:

- HEV: Toyota Prius, Toyota Camry Hybrid, Toyota Highlander Hybrid, Honda Civic Hybrid, Honda CR-Z Sport Hybrid, Honda Insight, Ford Escape Hybrid, and Ford Fusion Hybrid

- EV: Nissan Leaf, Tesla Roadster, Coda, and Mitsubishi MiEV

- FCV: Toyota FCHV, Ford Focus, GM HydroGen3, and Honda FCX

Because of the intended use of FSC for long-range scenario analysis with uncertain fleets, the vehicle generation strategy is not to constrain the modeling to existing or even prototype vehicles. The selected vehicle attributes thus include not only the probable but also the possible range of characteristics. In other words, we set the bounds wide enough to capture an uncertain future fleet. Note that in some cases, that means widening the original range of attributes tested in the PERE model (such as for hybrid thresholds).

The key parameters varied over vehicles for FSC shape sensitivity testing are:

1. Vehicle weight

2. Combustion engine size (displacement)

3. Engine indicated efficiency (the thermodynamic efficiency limit of the engine)

4. Electric motor peak power

5. Fuel cell power rating

6. Hybrid threshold (the power demand at which the engine or fuel cell is required in addition to the motor in an HEV or FCV) 
7. Transmission type (automatic or manual)

8. Fuel type (gasoline or diesel - also indicates spark-ignition or compression-ignition)

9. Power accessory load (such as air conditioning) 10. Road Load Coefficients (also used in VSP calculation)

11. Model year (which impacts engine and torque parameters through assumed trends)

Other parameters included in the PERE model are not varied due to low model sensitivity [4] or no published information on expected changes to the value. Some combustion engine characteristics are adjusted within PERE based on the vehicle model year (engine friction, enrichment threshold, peak torque, and peak power). The RLC coefficients for VSP calculation (see Equation 1) are based on EPA documentation [27] or estimated from the vehicle weight as described in the PERE documentation [4]. For fuel types other than gasoline or diesel (such as electricity), PERE converts consumed energy to gasoline equivalent units using an assumed energy density for gasoline of $32.7 \mathrm{MJ} / \mathrm{L}$.

The ranges of tested values of vehicle parameters are:

- Model year: 2005 to 2040

- Fuel type: gasoline, diesel

- Transmission type: manual, automatic

- Powertrain type: conventional ICE, hybrid, electric, fuel cell

- Engine size: 1.0 to 4.5 liters

- Vehicle curb weight: 2,000 to 5,000 lbs

- Road load method: weight-based and RLC

- Hybrid threshold: 1 to $6 \mathrm{~kW}$

- Motor peak power: 10 to $215 \mathrm{~kW}$

- Fuel cell power rating: 60 to $155 \mathrm{~kW}$

- Accessory load: 0.75 to $4 \mathrm{~kW}$

- Engine indicated efficiency: 0.4 to 0.6 gasoline, 0.45 to 0.6 diesel

The range of vehicle characteristics is tested over a set of 145 vehicles (not every possible combination of characteristics is modeled). The vehicles represent a range from very small neighborhood electric vehicles to large pickup trucks and Sports Utility Vehicles. Note that these parameters are modeled over their range of values, not simply at the extremes. While the ranges are wide compared to probable vehicle attributes, they also include the set of expected vehicles. Space constraints prevent inclusion of the full table of modeled vehicle attributes. However, vehicles of key interest are included below in Table 1.

\subsection{Fuel-Speed Curve Calculation}

The fuel speed curves are calculated from the model output as follows. Let $f_{b}$ be the PERE-modeled fuel consumption rate (in $\mathrm{kg} / \mathrm{second}$ ) in VSP bin $b$, where $b \in B$ and $B$ is the set of 17 VSP bins. This is (e) in Figure 1 . For EV and FCV, note that $f_{b}$ is presented in gasolineequivalent units. Let $t_{b}$ be the amount of driving time (in seconds) spent in VSP bin $b$ for a given 
321

322

323

324

325

326

327

328

329

330

331

332

333

334

335

336

337

338

339

340

341

342

343

344

345

346

347

348

349

350

351

352

353

354

355

356

357

driving schedule - (f) in Figure 1. Then the modeled fuel consumption (in kg) for that driving schedule is calculated

$$
f=\sum_{b \in B}\left(t_{b} \cdot f_{b}\right)
$$

For a given fuel density of $d_{f}$ in $\mathrm{kg} /$ gallon and a driving schedule distance of $D$ in miles, the fuel economy $F E$ (in gasoline-equivalent miles per gallon - mpg) for that driving schedule is then calculated

$$
F E=\frac{D \cdot d_{f}}{f}
$$

This is (g) in Figure 1 . We use $d_{f}=0.744 \mathrm{~kg} / \mathrm{L}$ for gasoline and $d_{f}=0.811 \mathrm{~kg} / \mathrm{L}$ for diesel from the PERE model, which converts to $d_{f}=2.82 \mathrm{~kg} /$ gallon and $d_{f}=3.07 \mathrm{~kg} /$ gallon, respectively. The average speed for the driving schedule, $v$, is simply $v=\frac{3600 \cdot D}{\sum_{b \in B} t_{b}}$. Note that the driving schedule is indicative of both average speed and speed variability at varying levels of congestion for typical conditions (see Section 2.1).

This fuel modeling approach creates discrete FE-speed data points, so a curve fit is applied to establish a full FSC - (h) in Figure 1. We fit the FSC to an exponentiated $4^{\text {th }}$-order polynomial functional form, following previous emissions modeling research [5], [7], [29]. The functional form is

$$
F E=\exp \left(\sum_{i=0}^{4} \alpha_{i} v^{i}\right)
$$

where $v$ is the average travel speed in mph and $\alpha_{i}$ are fitted parameters. The FSC are fit to this functional form using an iteratively reweighted least squares method. Separate fits are made for freeway and arterial driving schedules. Freeway driving schedules include MOVES and OR-217 sources. Arterial driving schedules are sourced from MOVES only.

Since average fuel economy is an input to the GreenSTEP model, the FSC are only used to adjust fuel economy for varying congestion levels (see Section 2.3). Therefore, we need not calculate absolute fuel economy, but simply how the fuel economy varies with average speed. To do this, we scale the freeway FSC to the modeled FE at the average speed of the "highway" EPA test driving schedule (HFET) - $48.2 \mathrm{mph}$ [11]. For arterials we take a similar approach, using a reference speed $24.4 \mathrm{mph}$. For FSC normalization to a reference speed $v_{r e f}$, the normalized fuel economy, $F E_{\text {norm }}$, is calculated

$$
F E_{\text {norm }}=\exp \left(\sum_{i=1}^{4} \alpha_{i}\left(v^{i}-v_{\text {ref }}^{i}\right)\right)
$$




\section{Results}

359

360

361

362

363

364

365

\subsection{Fuel Economy and Average Speed}

Figure 2 shows the FE-speed data points for all vehicles using all driving schedules. The figure is segmented by powertrain type, with different symbols to represent the different driving schedule sources and FE in gasoline-equivalent units. From Figure 2, we see that EV have the highest fuel economy and ICE the lowest. EV also have the widest range of fuel economies for the modeled vehicles (particularly at lower speeds). For each powertrain type the fuel economy values are fairly steady across the range of average speeds, with the exception of EV.

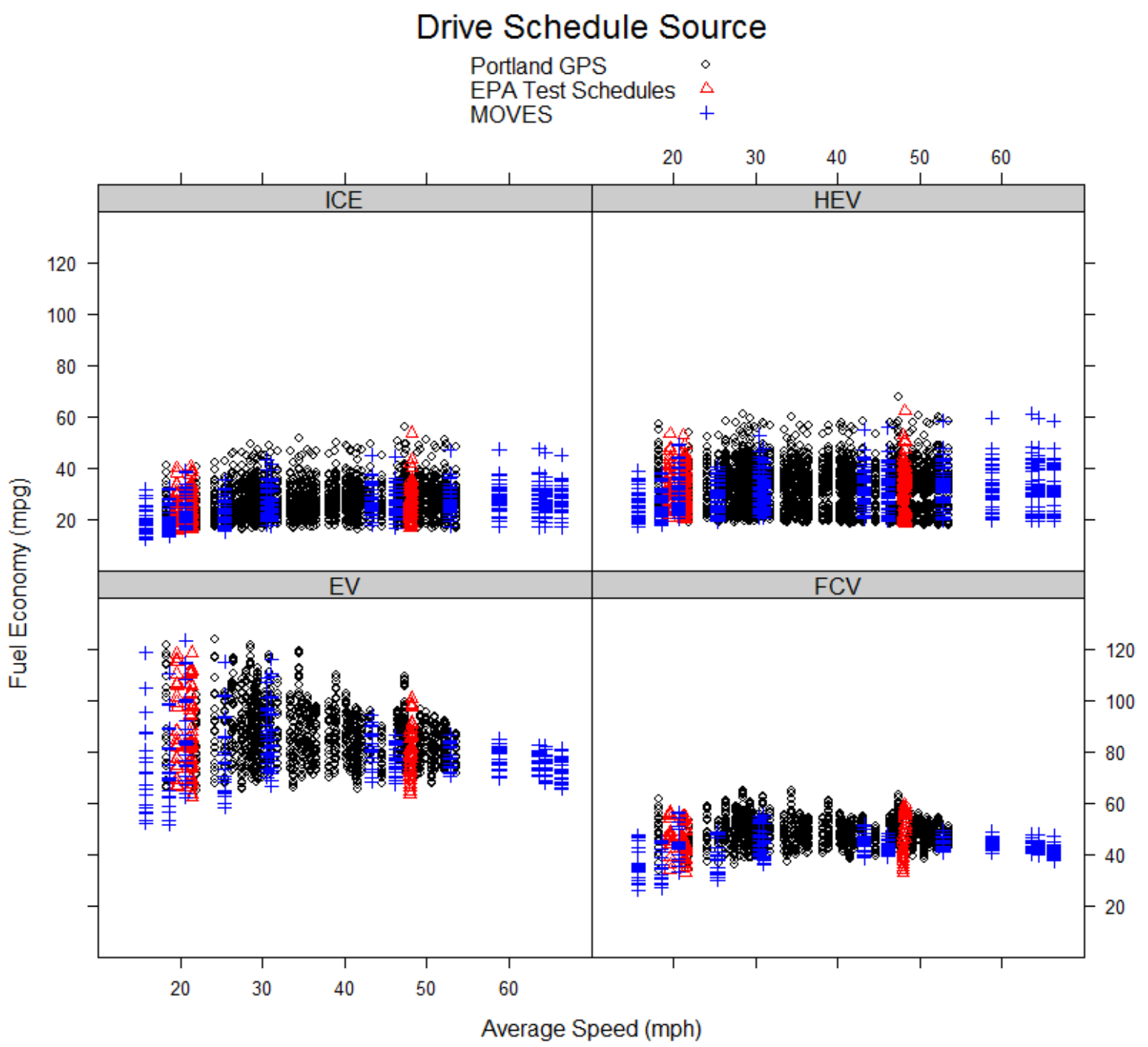

Figure 2. Fuel Economy vs. Average Speed by Powertrain Type for All Driving Schedules

Figure 3 presents the same data, but normalized to the freeway reference speed and excluding MOVES arterial driving schedules. Higher values of normalized FE indicate improved 
but with some of the inter-vehicle overall fuel economy differences removed - thus illuminating the impacts of average speed. ICE vehicle FE is generally flat from free-flow speed down to around $35 \mathrm{mph}$, at which point FE begins to decrease. For HEV the FE is nearly flat for all except the lowest-speed MOVES driving schedule. EV fuel economy increases with decreasing speed from free-flow conditions, down to around 20-30 mph. FCV fuel economy also increases somewhat as speed decreases.

\section{Drive Schedule Source}
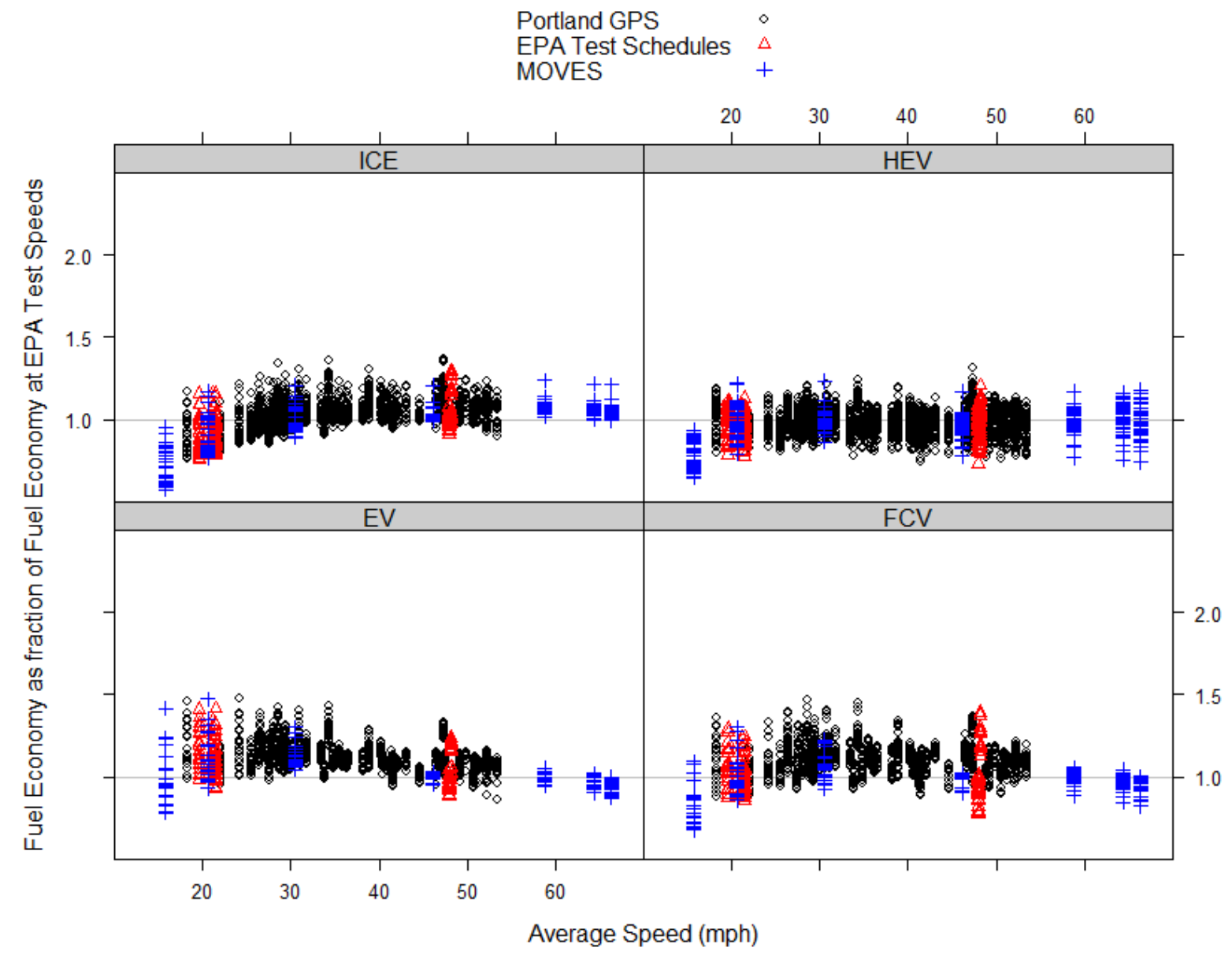

Figure 3. Fuel Economy (Normalized to Reference Speed) vs. Average Speed by Powertrain Type for Freeways

\subsection{Fuel-Speed Curves}

This section presents the fitted FSC from Equation 4. Two example fits for freeway FSC are shown in Figure 4. Here, two fitted FSC are shown along with the base data (using the MOVES and OR-217 driving schedules). The example low-congestion-efficiency ICE vehicle is a heavy, high-powered gasoline-fueled passenger car. The fit has an approximate R-squared value of 0.96 (calculated as Nagelkerke’s generalized R-squared). The example high-congestion- 
efficiency ICE vehicle is a diesel-fueled passenger truck with moderate power and weight. This fit has a generalized R-squared value of 0.86 .

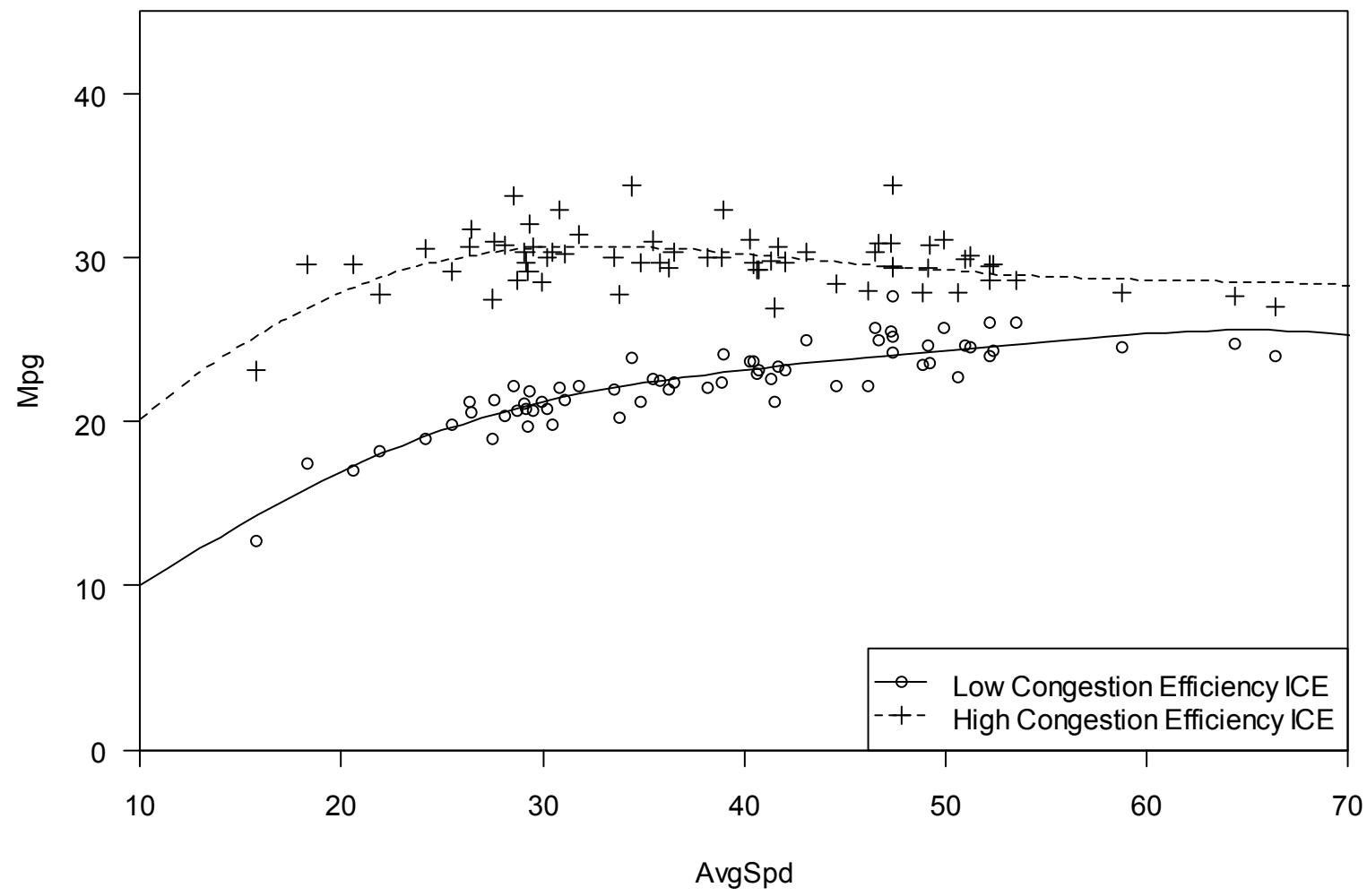

Figure 5 shows fitted freeway FSC for all modeled vehicles, segmented by powertrain type (again in gasoline-equivalent mpg). There is a wide variety of FE values and FSC shapes, as expected from Figure 2 (note the different vertical scales). Generally, ICE vehicles have varying relationships with speed (positive or negative) for speeds above $30 \mathrm{mph}$, and decreasing $\mathrm{FE}$ at 394 lower speeds below $30 \mathrm{mph}$. HEV are less sensitive to congestion, with some vehicles' FE not decreasing until below $20 \mathrm{mph}$. Some HEV have about the same FE performance as ICE vehicles 396 - particularly those with low hybrid thresholds. EV and FCV both show increasing FE with decreasing speed in Figure 5, down to a speed in the range of 20-40 mph. 

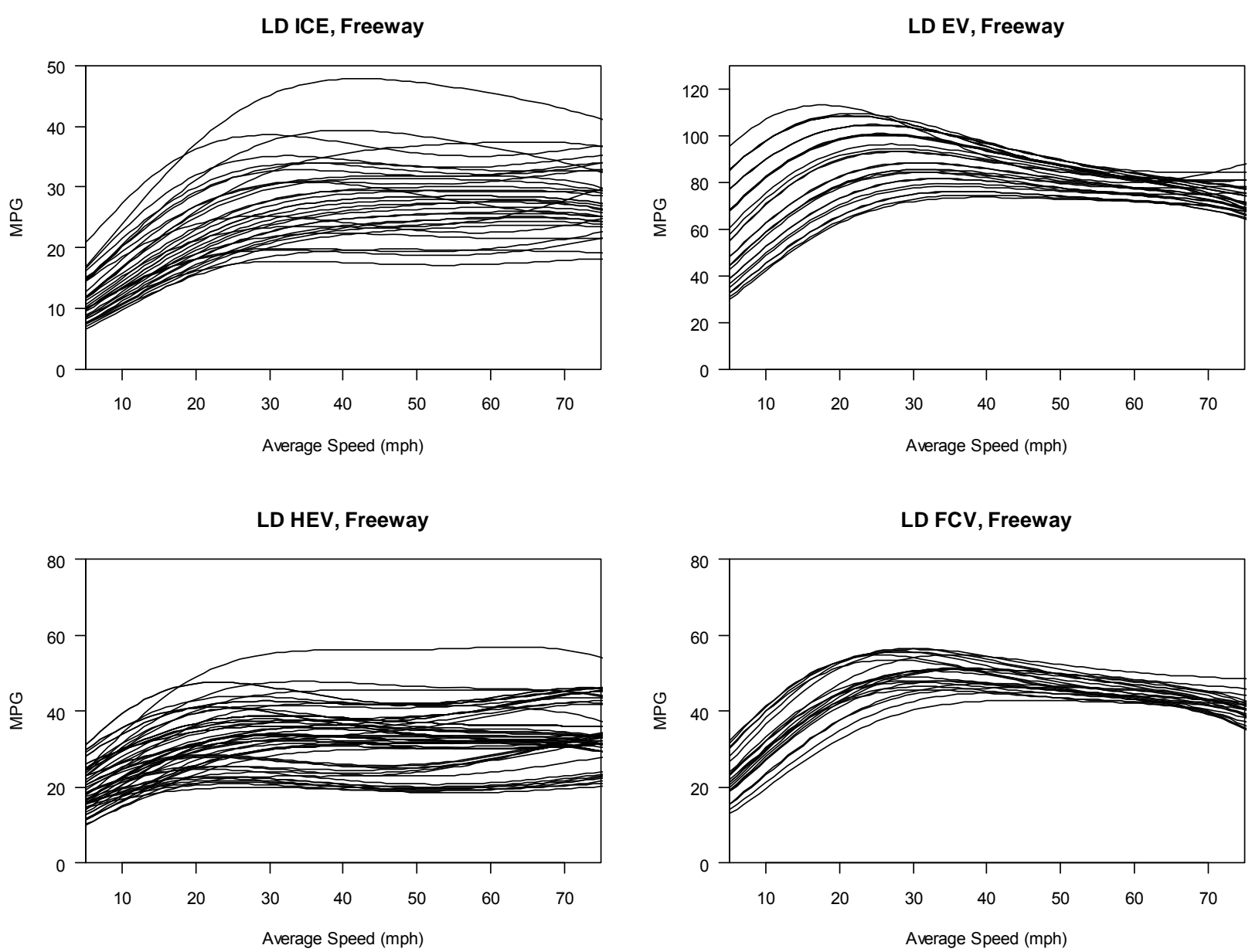

Figure 5. Modeled Individual Freeway FSC by Powertrain Type

\subsection{Sensitivity of Fuel Economy in Congestion to Vehicle Characteristics}

Fuel economy can vary widely among vehicles for any one driving schedule, as illustrated in Figure 2. This is due to variability in both fuel rates and VSP distributions of operating time. In this section we examine how vehicle characteristics influence the Fuel-Speed data points. Of particular interest is which vehicle characteristics impact the shape of the FSC i.e., which characteristics most affect relative vehicle performance in congestion. This is different from which vehicle characteristics impact overall fuel economy, and sometimes shows opposite effects. For example, vehicle parameters that mostly improve FE at higher speeds (decreased drag coefficients, for example) will result in poorer relative FE in congestion. hybrid threshold, and accessory load are the vehicle characteristics that have the most impact on the fuel economy effects of congestion. Higher vehicle weight, engine size, and accessory load all decrease relative performance in congestion for ICE vehicles, while higher RLC increase relative performance. Compared to cars, passenger trucks and SUV's tend to have more weight and engine power (which both reduce performance in congestion), but also higher RLC (which 
improves relative performance in congestion by disproportionately decreasing efficiency at high speeds). Higher motor peak power slightly increases relative congestion performance for EV, but higher fuel cell power rating decreases relative congestion performance for FCV.

HEV performance in congestion increases with hybrid threshold (since more low-power driving is powered by recovered energy). For HEV the motor and battery characteristics combined with the driving patterns will determine the true hybrid threshold. Assuming HEV improve over time to allow higher hybrid thresholds, the relative HEV performance in congestion will improve as well. Unlike ICE vehicles, HEV can improve their relative FE in congestion with larger engine sizes, because they can utilize the larger ICE nearer optimum efficiency for high power loads but turn off the combustion engine during low-power driving events in congestion. In this study, motor peak power was not a limiting factor in relative efficiency for HEV. High accessory power loads notably degrade the relative efficiency in congestion for fuel efficient vehicles, since a greater portion of total energy demand in congestion is from the static accessory load. Since much of the expected accessory load is from air conditioning usage, improvements over time such as advanced window glazings and cabin ventilation [28] can increase the relative FE in congestion for advanced vehicles.

Power demands vary due to external vehicle forces only (mass and RLC inputs), while fuel rates are influenced by all vehicle attributes. From Equation 1, the RLC and vehicle mass have larger impacts at higher speeds (the impact of RLC “ $C$ ” increases with the cube of speed). The impact of acceleration, however, is independent of mass or RLC. Thus, the VSP distribution of high-speed freeway driving schedules (with higher speeds and fewer accelerations) is more impacted by vehicle characteristics (mass and RLC) than the VSP distribution of arterial driving schedules (with more accelerations and lower speeds). More generally, the VSP distribution of vehicle activity in uncongested driving conditions is more impacted by vehicle characteristics than in congested driving conditions. The same holds for arterial versus freeway driving, with freeway driving more impacted by vehicle characteristics.

As demonstrated in Figure 5, there is a range of potential FSC shapes for each vehicle type, depending on the specific vehicle characteristics. Projecting this array of characteristics for future vehicle fleets in scenario analysis is impractical. The next section describes a suggested approach for incorporating these FSC into scenario analysis.

\section{Applying Fuel-Speed Curves for Scenario Analysis}

This section describes a recommended method for applying advanced-vehicle FSC for scenario analysis, considering the range of plausible curve shapes shown in Section 4. The recommended approach is to use minimum/maximum sensitivity normalized FSC as the bounds of congestion effects. Interpolating between these extreme curves provides speed-based FE adjustment factors to calculate congestion effects on overall fuel economy.

The interpolation distance between the bound FSC is based on a new model input, "Congestion Efficiency", which describes the projected performance of each vehicle type in congestion, with respect to "extreme case" vehicles. Congestion Efficiency ranges from 0 for 
454 poorest performance to 1 for maximum relative efficiency performance. Using Congestion 455 Efficiency $C E$ and upper and lower bound normalized FSC with curve fit parameters $\alpha_{U, i}$ and $456 \alpha_{L, i}$, respectively, the interpolated normalized FSC curve is calculated

$$
F E=C E \cdot \exp \left(\sum_{i=0}^{4} \alpha_{U, i} v^{i}\right)+(1-C E) \exp \left(\sum_{i=0}^{4} \alpha_{L, i} v^{i}\right)
$$

460 The determination of $C E$ in scenario analysis is based on the sensitivities described in Section 461 4.3. This approach avoids introducing numerous new vehicle parameters to the scenario analysis, 462 while still allowing some assumptions about the future vehicle fleet to inform the congestion 463 adjustment values.

464 We selected extreme-case vehicles for FSC bounds based on comparison of the FSC 465 shapes and vehicle attributes. Those vehicles selected are the modeled vehicles of each vehicle 466 type with the highest and lowest relative FE in heavy congestion as compared to FE at free-flow 467 speed (for each facility type). The vehicle characteristics and FSC fit parameters for the selected 468 vehicles are shown in Table 1. The corresponding upper-bound and lower-bound FSC are shown 469 in Figure 6. The selected bounding vehicles in Table 1 are not the most extreme combinations of 470 attributes possible. Rather, they are modeled mixes of vehicle attributes considered possible (if 471 not probable) based on the literature. 
472 Table 1. Extreme-Case Vehicles: Characteristics and FSC Fit Parameters

\begin{tabular}{|c|c|c|c|c|c|c|c|c|}
\hline \multirow[b]{3}{*}{ Congestion Efficiency } & \multicolumn{8}{|c|}{ Freeways } \\
\hline & \multicolumn{2}{|c|}{ ICE* } & \multicolumn{2}{|c|}{$\mathrm{HEV}^{*}$} & \multicolumn{2}{|c|}{$\mathrm{EV}^{* *}$} & \multicolumn{2}{|c|}{$\mathrm{FCV}^{* *}$} \\
\hline & Low & High & Low & High & Low & High & Low & High \\
\hline Passenger Car/Truck & Car & Truck & Car & Car & Car & Car & Car & Car \\
\hline Curb Weight (Ibs) & 5,000 & 2,500 & 2,504 & 2,000 & 3,800 & 2,000 & 3,000 & 2,000 \\
\hline Engine Displ. (L) & 4.5 & 2.0 & 1.1 & 2.0 & NA & NA & NA & NA \\
\hline RLC: A & 156.46 & 235.01 & 156.46 & 156.46 & 156.46 & 156.46 & 156.46 & 156.46 \\
\hline RLC: B & 2.002 & 3.039 & 2.002 & 2.002 & 2.002 & 2.002 & 2.002 & 2.002 \\
\hline RLC: C & 0.493 & 0.748 & 0.493 & 0.493 & 0.493 & 0.493 & 0.493 & 0.493 \\
\hline $\begin{array}{l}\text { Motor Peak Power/ } \\
\text { Fuel Cell Rating (kW) }\end{array}$ & NA & NA & 68 & 10 & 80 & 100 & 140 & 40 \\
\hline Hybrid Threshold (kW) & NA & NA & 2 & 4 & NA & NA & NA & NA \\
\hline Accessory Power (kW) & 0.75 & 0.75 & 4 & 0.75 & 4 & 0.75 & 4 & 0.75 \\
\hline Total Peak Power (kW) & 220 & 98 & 123 & 108 & 80 & 100 & 140 & 40 \\
\hline Specific Power (W/kg) & 97 & 86 & 108 & 119 & 46 & 110 & 103 & 44 \\
\hline$\alpha_{0}$ & 1.514 & 2.331 & 1.892 & 3.122 & 2.911 & 4.236 & 1.984 & 3.048 \\
\hline$\alpha_{1}$ & 0.1112 & 0.0809 & 0.1321 & 0.0667 & 0.1132 & 0.0511 & 0.1324 & 0.0955 \\
\hline$\alpha_{2}$ & -0.0029 & -0.0025 & -0.0041 & -0.0025 & -0.0034 & -0.0019 & -0.0037 & -0.0032 \\
\hline$a_{3}$ & $3.63 E-5$ & $2.94 \mathrm{E}-5$ & $5.78 \mathrm{E}-5$ & $3.44 \mathrm{E}-5$ & $4.55 \mathrm{E}-5$ & $2.41 \mathrm{E}-5$ & $4.60 \mathrm{E}-5$ & 4.27E-5 \\
\hline \multirow[t]{3}{*}{$\alpha_{4}$} & $-1.73 \mathrm{E}-7$ & $-1.15 \mathrm{E}-7$ & $-2.90 \mathrm{E}-7$ & $-1.63 \mathrm{E}-7$ & $-2.27 \mathrm{E}-7$ & $-1.04 \mathrm{E}-7$ & $-2.18 \mathrm{E}-7$ & $-2.00 \mathrm{E}-7$ \\
\hline & \multicolumn{8}{|c|}{ Arterial } \\
\hline & \multicolumn{2}{|c|}{ ICE* $^{*}$} & \multicolumn{2}{|c|}{$\mathrm{HEV}^{*}$} & \multicolumn{2}{|c|}{$\mathrm{EV}^{* *}$} & \multicolumn{2}{|c|}{$\mathrm{FCV}^{* *}$} \\
\hline Congestion Efficiency & Low & High & Low & High & Low & High & Low & High \\
\hline Passenger Car/Truck & Car & Truck & Car & Car & Car & Car & Car & Car \\
\hline Curb Weight (lbs) & 3,750 & 2,500 & 3,000 & 3,020 & 3,800 & 2,000 & 3,000 & 2,000 \\
\hline Engine Displ. (L) & 4.5 & 2.0 & 1.8 & 1.3 & NA & NA & NA & NA \\
\hline RLC: A & 156.46 & 235.01 & 156.46 & 154.69 & 156.46 & 156.46 & 156.46 & 156.46 \\
\hline RLC: B & 2.002 & 3.039 & 2.002 & 1.977 & 2.002 & 2.002 & 2.002 & 2.002 \\
\hline RLC: C & 0.493 & 0.748 & 0.493 & 0.487 & 0.493 & 0.493 & 0.493 & 0.493 \\
\hline $\begin{array}{l}\text { Motor Peak Power/ } \\
\text { Fuel Cell Rating (kW) }\end{array}$ & NA & NA & 60 & 10 & 80 & 100 & 140 & 40 \\
\hline Hybrid Threshold (kW) & NA & NA & 2 & 2 & NA & NA & NA & NA \\
\hline Accessory Power (kW) & 4 & 0.75 & 4 & 0.75 & 4 & 0.75 & 4 & 0.75 \\
\hline Total Peak Power (kW) & 220 & 98 & 148 & 76 & 80 & 100 & 140 & 40 \\
\hline Specific Power (W/kg) & 129 & 86 & 109 & 55 & 46 & 110 & 103 & 44 \\
\hline$\alpha_{0}$ & 1.392 & 2.331 & 1.803 & 2.71 & 2.911 & 4.236 & 1.984 & 3.048 \\
\hline$\alpha_{1}$ & 0.1145 & 0.0809 & 0.1204 & 0.0765 & 0.1132 & 0.0511 & 0.1324 & 0.0955 \\
\hline$\alpha_{2}$ & -0.0029 & -0.0025 & -0.0034 & -0.0031 & -0.0034 & -0.0019 & -0.0037 & -0.0032 \\
\hline$\alpha_{3}$ & $3.45 \mathrm{E}-5$ & $2.94 \mathrm{E}-5$ & 4.36E-5 & 4.77E-5 & 4.55E-5 & $2.41 \mathrm{E}-5$ & 4.60E-5 & 4.27E-5 \\
\hline$\alpha_{4}$ & $-1.55 E-7$ & $-1.15 E-7$ & $-2.06 \mathrm{E}-7$ & $-2.42 \mathrm{E}-7$ & $-2.27 \mathrm{E}-7$ & $-1.04 \mathrm{E}-7$ & $-2.18 \mathrm{E}-7$ & $-2.00 \mathrm{E}-7$ \\
\hline
\end{tabular}

* Gasoline-fueled, automatic transmission, engine indicated efficiency of 0.4, model year 2010

${ }^{* *}$ EV and FCV are the same vehicles for arterials and freeways, model year 2010 
LD ICE Freeway

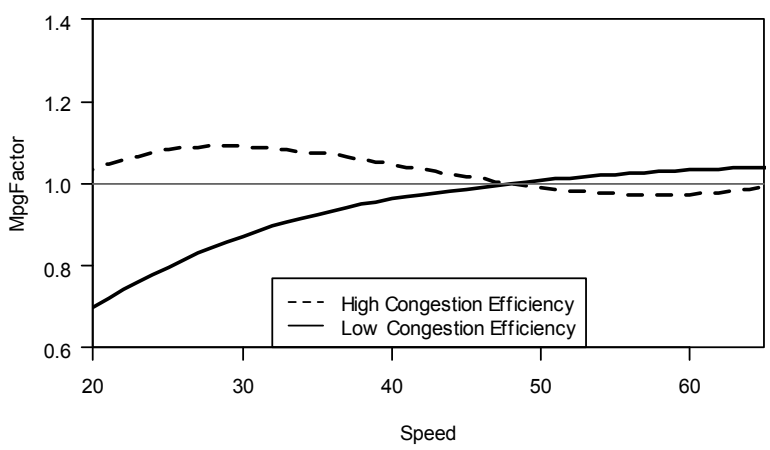

LD EV Freeway

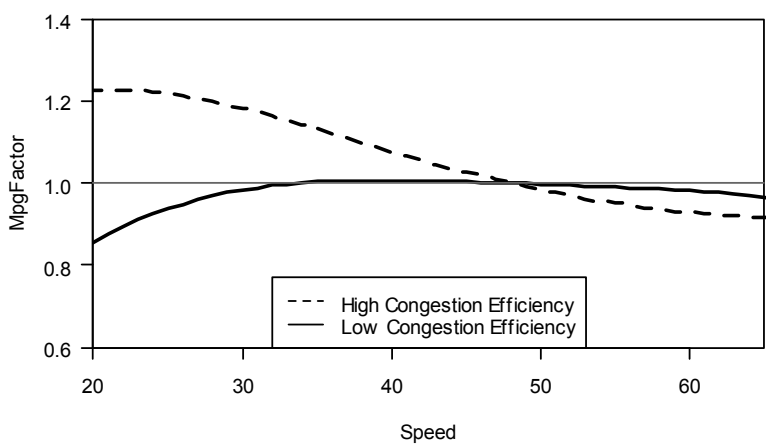

LD ICE Arterial

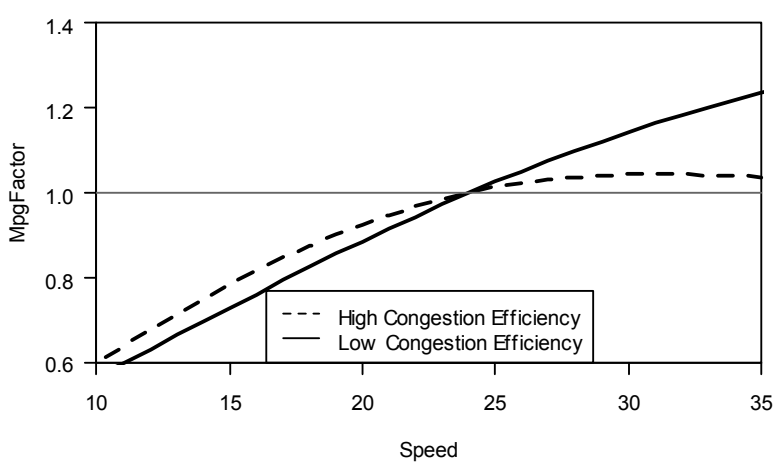

LD EV Arterial

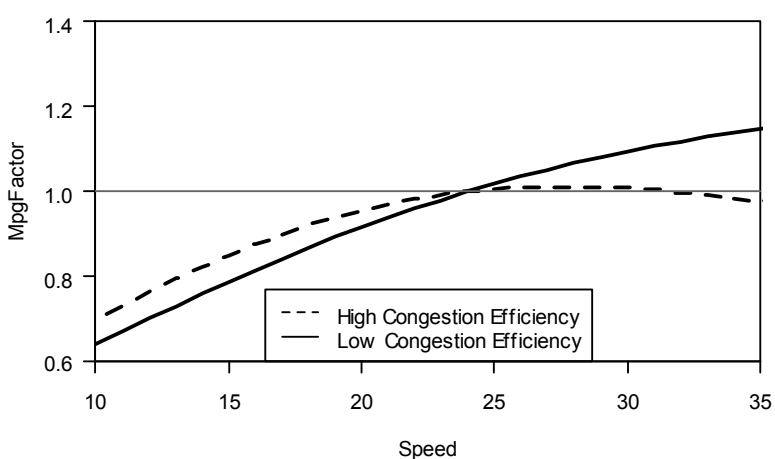

LD HEV Freeway

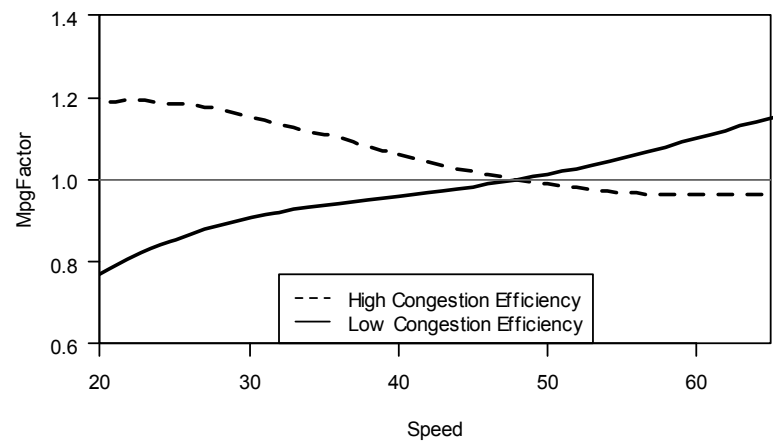

LD FCV Freeway

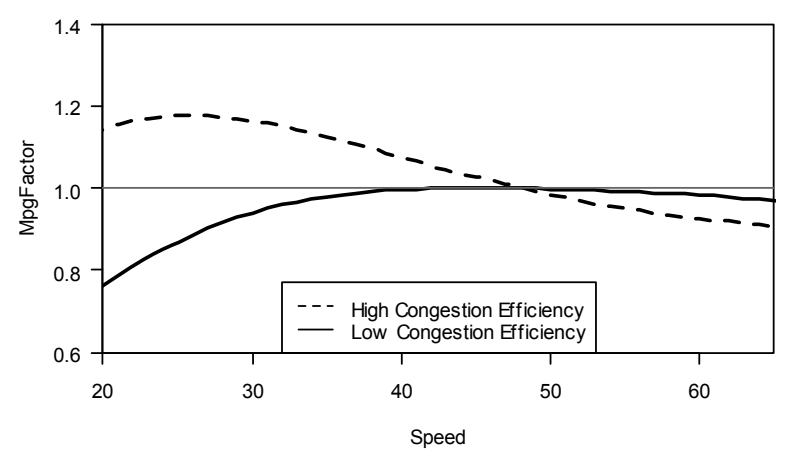

LD HEV Arterial

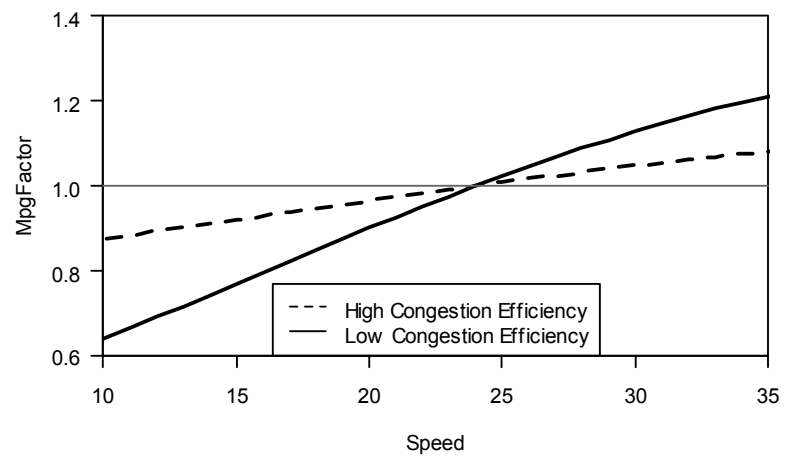

LD FCV Arterial

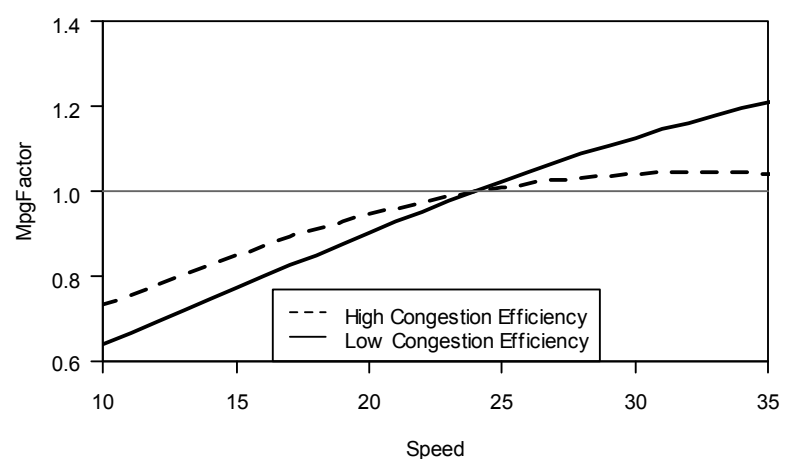


Table 2 lists the vehicle characteristics that are expected to impact the relative efficiency in congestion $(C E)$ for each vehicle powertrain type. This table is based on sensitivity analysis of the modeled vehicle attributes and FSC. Qualitative projection of these attributes can be used to set the new model input, Congestion Efficiency, between 0 and 1. The median Congestion Efficiency value is 0.5, which puts the FE adjustment curve midway between the extreme curves shown in Figure 6. If we expect, for example, average HEV to get lighter over time, we can set the Congestion Efficiency to trend upward for future model years. Note again that $C E$ is increased both by attributes that improve $\mathrm{FE}$ in congestion and by attributes that disproportionately decrease FE at higher speeds.

Table 2. Vehicle Characterisitcs Influencing Relative Congestion Efficiency

\begin{tabular}{|c|c|c|}
\hline Powertrain type & Low Relative Congestion Efficiency & High Relative Congestion Efficiency \\
\hline ICE & $\begin{array}{c}\text { heavier weight, larger engine, lower RLC, } \\
\text { gasoline fuel, higher accessory loads, } \\
\text { earlier model year }\end{array}$ & $\begin{array}{l}\text { lighter weight, smaller engine, higher } \\
\text { RLC, diesel fuel, lower accessory loads, } \\
\text { later model year }\end{array}$ \\
\hline HEV & $\begin{array}{l}\text { heavier weight, smaller ICE, lower RLC, } \\
\text { lower hybrid threshold, gasoline fuel, } \\
\text { higher accessory loads, earlier model year }\end{array}$ & $\begin{array}{l}\text { lighter weight, larger ICE, higher RLC, } \\
\text { higher hybrid threshold, diesel fuel, } \\
\text { lower accessory loads, later model year }\end{array}$ \\
\hline EV & $\begin{array}{c}\text { heavier weight, lower RLC, higher } \\
\text { accessory loads }\end{array}$ & $\begin{array}{l}\text { lighter weight, higher RLC, lower } \\
\text { accessory loads }\end{array}$ \\
\hline FCV & $\begin{array}{l}\text { heavier weight, higher fuel cell power } \\
\text { rating, lower RLC, higher accessory loads }\end{array}$ & $\begin{array}{l}\text { lighter weight, lower fuel cell power } \\
\text { rating, higher RLC, lower accessory loads }\end{array}$ \\
\hline
\end{tabular}

486

As a final consideration, we examine the potential impacts of these FSC on overall FE. Using a Congestion Efficiency of 0.5, at $25 \mathrm{mph}$ the freeway ICE FE adjustment factor is 0.94 and all three advanced powertrain vehicle types have FE adjustments over 1 (i.e. efficiency benefits). On arterials, the minimum adjustment factor at $20 \mathrm{mph}$ (for ICE) is 0.92 . Thus, the potential adjustments to FE for typical congestion are small. With evolving vehicle fleets containing more advanced vehicles, it is unlikely that the net effect of congestion on FE will be substantially detrimental - and the net effect could be beneficial.

\section{Conclusions}

This paper describes research undertaken to establish plausible fuel-speed curves (FSC) for advanced vehicles, to be used in long-term transportation scenario analysis. We use the PERE fuel consumption model with real-world driving schedules and a range of advanced vehicle characteristics to estimate vehicle fuel economy in varying traffic conditions. The fuel-speed data points are then used to generate normalized fuel economy versus average speed curves for each of 145 modeled vehicles.

Analysis of the FSC shows that advanced powertrain vehicles are expected to perform better in congestion than ICE vehicles (with respect to FE at free-flow speeds). Many ICE vehicles do not lose fuel efficiency until traffic slows to about $30 \mathrm{mph}$. HEV are less sensitive to 
504

505

506

507

average speed changes than ICE vehicles, and tend to maintain their fuel efficiency down to 20 mph, due to recaptured braking energy. Fuel efficiency increases for EV down to about 20-30 mph, below which it degrades. FCV have similar FE effects to EV, though with less sensitivity to speed.

Besides powertrain type, congestion effects vary with other vehicle characteristics as well. Relative fuel efficiency at lower speeds improves for vehicles with lighter weight, smaller engines, higher hybrid thresholds, and lower accessory loads (such as air conditioning). Relative performance in congestion can also improve with attributes that disproportionately decrease FE at higher speeds, such as higher aerodynamic drag and rolling resistance factors.

Considering the normalized FSC sensitivity to multiple attributes, we propose a bounded approach for applying the modeled FSC in scenario analysis. In the proposed method, FE adjustments are an interpolation between extreme-case FSC, based on projection of relative congestion efficiency. This allows adjustment for vehicle trends over time without requiring specificity in the vehicle fleet characteristics.

In conclusion, the modeled FSC show that advanced powertrain vehicles can reduce or reverse the fuel efficiency losses associated with typical roadway congestion. On the other hand, advanced vehicles with certain characteristics (heavy and with high accessory power loads, for example) can still have poor relative performance in congestion. The results of this research can assist with broader analysis of the role these differences will play in total fuel consumption and emissions from roadway travel.

\section{References}

[1] D. Schrank, T. Lomax, and B. Eisele, “Urban Mobility Report 2011,” Texas Transportation Institute, College Station, TX, Sep. 2011.

[2] S. E. Plotkin and M. K. Singh, "Multi-Path Transportation Futures Study: Vehicle Characterization and Scenario Analyses,” Argonne National Laboratory (ANL), 2009.

[3] B. Gregor, "Greenhouse Gas Statewide Transportation Emissions Planning Model (GreenSTEP Model) Documentation - Draft.” Oregon Department of Transportation, Nov2010.

[4] E. Nam and R. Giannelli, "Fuel Consumption Modeling of Conventional and Advanced Technology Vehicles in the Physical Emission Rate Estimator (PERE)," U.S. Environmental Protection Agency, Draft EPA420-P-05-001, Feb. 2005.

[5] M. Barth and K. Boriboonsomsin, "Real-World Carbon Dioxide Impacts of Traffic Congestion," Transportation Research Record: Journal of the Transportation Research Board, vol. 2058, pp. 163-171, 2008.

[6] M. Barth, G. Scora, and T. Younglove, "Estimating emissions and fuel consumption for different levels of freeway congestion," Transportation Research Record: Journal of the Transportation Research Board, vol. 1664, pp. 47-57, 1999.

[7] A. Bigazzi and M. Figliozzi, "An Analysis of the Relative Efficiency of Freeway Congestion Mitigation as an Emissions Reduction Strategy," in 90th Annual Meeting of the Transportation Research Board, Washington, D.C., 2011. 
[8] T. Barlow and P. Boulter, "Emissions factors 2009: Report 2 - a review of the averagespeed approach for estimating hot exhaust emissions," UK Department for Transport, Research report PPR355, Jun. 2009.

[9] R. Smit, A. L. Brown, and Y. C. Chan, "Do air pollution emissions and fuel consumption models for roadways include the effects of congestion in the roadway traffic flow?," Environmental Modelling and Software, vol. 23, no. 10-11, pp. 1262-1270, 2008.

[10] U.S. Environmental Protection Agency, "Motor Vehicle Emission Simulator (MOVES) 2010 User’s Guide,” Washington, D.C., EPA-420-B-09-041, Dec. 2009.

[11] U.S. Environmental Protection Agency, "Final Technical Support Document: Fuel Economy Labeling of Motor Vehicle Revisions to Improve Calculation of Fuel Economy Estimates,” Washington, D.C., EPA420-R-06-017, Dec. 2006.

[12] S. C. Davis, S. W. Diegel, and R. G. Boundy, "Transportation Energy Data Book: Edition 29,” Oak Rige National Laboratory, Oak Ridge, TN, ORNL-6985, Jul. 2010.

[13] T. Markel et al., "ADVISOR: a systems analysis tool for advanced vehicle modeling," Journal of Power Sources, vol. 110, no. 2, pp. 255-266, Aug. 2002.

[14] M. Singh, A. Vyas, and E. Steiner, "VISION Model: Description of Model Used to Estimate the Impact of Highway Vehicle Technologies and Fuels on Energy Use and Carbon Emissions to 2050," Argonne National Laboratory, ANL/ESD/04-1, Dec. 2003.

[15] M. Earleywine, J. Gonder, T. Markel, and M. Thornton, "Simulated fuel economy and performance of advanced hybrid electric and plug-in hybrid electric vehicles using in-use travel profiles," in Vehicle Power and Propulsion Conference (VPPC), 2010 IEEE, 2010, pp. 1-6.

[16] C. Samaras and K. Meisterling, "Life Cycle Assessment of Greenhouse Gas Emissions from Plug-in Hybrid Vehicles: Implications for Policy," Environmental Science \& Technology, vol. 42, no. 9, pp. 3170-3176, May 2008.

[17] C. Silva, M. Ross, and T. Farias, "Evaluation of energy consumption, emissions and cost of plug-in hybrid vehicles," Energy Conversion and Management, vol. 50, no. 7, pp. 16351643, Jul. 2009.

[18] A. Delorme, D. Karbowski, and P. Sharer, "Evaluation of fuel consumption potential of medium and heavy duty vehicles through modeling and simulation.," Argonne National Laboratory (ANL), 2010.

[19] G. Fontaras, P. Pistikopoulos, and Z. Samaras, "Experimental evaluation of hybrid vehicle fuel economy and pollutant emissions over real-world simulation driving cycles," Atmospheric Environment, vol. 42, no. 18, pp. 4023-4035, Jun. 2008.

[20] A. Alessandrini and F. Orecchini, "A driving cycle for electrically-driven vehicles in Rome," Proceedings of the Institution of Mechanical Engineers, Part D: Journal of Automobile Engineering, vol. 217, no. 9, pp. 781-789, Jan. 2003.

[21] M. Barth et al., "Development of a Modal-Emissions Model," Transportation Research Board, Project 25-11, Apr. 2000.

[22] H. C. Frey, A. Unal, J. Chen, S. Li, and C. Xuan, "Methodology for Developing Modal Emission Rates for EPA's Multi-Scale Motor Vehicle \& Equipment Emission System," U.S. Environmental Protection Agency, Ann Arbor, Michigan, EPA420-R-02-027, Aug. 2002.

[23] G. Song and L. Yu, "Estimation of Fuel Efficiency of Road Traffic by Characterization of Vehicle-Specific Power and Speed Based on Floating Car Data," Transportation Research 
Record: Journal of the Transportation Research Board, vol. 2139, no. 1, pp. 11-20, Dec. 2009.

[24] E. Nam, "Proof of Concept Investigation for the Physical Emission Rate Estimator(PERE) for MOVES," U.S. Environmental Protection Agency, Ann Arbor, Michigan, EPA420-R03-005, Feb. 2003.

[25] J. Koupal, L. Landman, E. Nam, J. Warila, E. Glover, and R. Giannelli, "MOVES2004 Energy and Emissions Inputs,” U.S. Environmental Protection Agency, Washington, D.C., EPA420-P-05-003, Mar. 2005.

[26] Oregon Department of Transportation, "Traffic Volumes and Vehicle Classification,” 24Aug-2010. [Online]. Available: http://highway.odot.state.or.us/cf/highwayreports/traffic_parms.cfm. [Accessed: 03-Nov2010].

[27] U.S. Environmental Protection Agency, "MOVES2010 Highway Vehicle Population and Activity Data,” Washington, D.C., EPA-420-R-10-026, Nov. 2010.

[28] R. Farrington and J. Rugh, "Impact of vehicle air-conditioning on fuel economy, tailpipe emissions, and electric vehicle range," in Earth Technologies Forum, WDC, 2000.

[29] S. Sugawara and D. Niemeier, "How much can vehicle emissions be reduced? Exploratory analysis of an upper boundary using an emissions-optimized trip assignment," Transportation Research Record, vol. 1815, pp. 29-37, 2002. 